\title{
The Evaluation of Mental Toughness and Goal Orientation in Students Licensed in Coaching Education Departments
}

\section{Zarife Tastan $^{1 *}$, Turhan Toros ${ }^{1}$, Inci Kesilmis ${ }^{2}$ \\ ${ }^{1}$ Department of Sports Sciences, Mersin University, Mersin, Turkey \\ ${ }^{2}$ Department of Physical Education and Sports, OsmaniyeKorkut Ata University, Osmaniye, Turkey \\ Study Area: Mersin, Turkey \\ Coordinates: $36^{\circ} 48^{\prime} \mathrm{N} ; 34^{\circ} 38^{\prime} \mathrm{E}$}

Key words: Resistance, Goal setting, Individual-team Training science

\section{Abstract}

The universe of the study consists of licensed studentathletes in coaching education who were a part of the six state universities in Turkey. Participants consist of 269 volunteer students selected by the easily available sampling method. Mental toughness Inventory in Sports was used to determine Mental Toughness. In order to determine goal orientation, Task and Ego Orientation in Sport Questionnaire were used. As per the analysis; between the "task" and "ego" sub-dimensions and the "confidence" subdimension positively at a medium level, between the "task" sub-dimension and the "commitment" sub-dimension positively at a moderate level, between the "ego" subdimension and the " commitment" sub-dimension. There was a weak negative correlation between the "task" and "ego" sub-dimensions and the "control" sub-dimension.

managers, and has been seen as an important prerequisite for continuous sporting success (Jones et al., 2007; Sheard, 2013). Sports environment can include many difficulties, stress and even failure concepts for athletes. For this reason, athletes should keep their mental toughness levels as high as possible in such adverse situations in order to achieve success or recover quickly (Crust, 2008). Generally, mental toughness is defined as a natural or developed psychological power that enables athletes to cope better than their opponents in conditions such as training and competition environment (Gucciardi, 2010). Although the phenomenon of mental toughness has been handled with different perspectives and various definitions in the literature, most of them are not based on any theory and are mostlyassociated with empirical findings.

The individual sets a goal about her own success or ability, by comparison with her own past performance standards or with others similar to his/her. According to goal orientation theory, people get a sense of accomplishment the moment they reach goals. Feelings of achievement are obtained as a result of the achievement of goals and its value is given according to the achievement of the goal by the athlete (Nicholls et al., 1989). The feeling of success or failure depends on the athlete's goal orientation. Success determines goal orientation when compared to both the person and the others (Nicholls, 1984).In fact, goal orientation is the objective with which a person evaluates one's success. The first dimension of goal orientation is task-oriented goals. To be successful, the athlete must work 
hard and put in the best effort. Success is in this process; pleasure is at work. Stephens and Bredemier (1996) state that athletes with high task orientation see themselves competent and enjoy taking part in sports. The athlete with high task orientation sees competitions as a chance to improve her skills. The second dimension of goal orientation is ego-oriented goals. The ego-oriented athlete gets a sense of accomplishment when gaining superiority over others. According to the research by Walling \& Duda (1995), athletes with high ego orientation become reluctant to compete when they feel that they cannot succeed. Such athletes consider winning or gaining superiority as greatness and want to do everything that needs to be done to win, even at the expense of the rules (Duda, 1992). Once the athletes fail to win or perceive themself to be superior, they may not continue her participation in the sport. According to Jagacinski \& Nicholls (1984), two independent factors of goal orientation are present in every athlete, and the degree to which each factor manifests itself is the athlete's goal orientation. In these two independent factors, task high-ego high, task high-ego low, task low-ego high, task low-ego low.

The sports environment can contain many difficulties, problems, stress and even failure concepts, especially for athletes. For this reason, athletes must keep their mental toughness as high as possible in the face of such adverse situations in order to achieve success or to recover quickly. In this study, the correlation between mental toughness and goal orientation in students who do team sports and individual sports will be revealed, and according to the results of the research, coaching education departments will give important clues in their self-assessment and development. At the same time, it will help the departments to make a more accurate evaluation in the selection of athletes-students. Thanks to the findings to be obtained in this research, it is thought that it will guide the researchers in future studies about team sports and students who do individual sports. The aim of this study was to determine the correlation between mental toughness and goal orientation in Coaching Education departments students whoare licensed in a team and individual sports.

\section{Methodology:}

In this study, the relational screening model was used to determine the correlation between mental toughness and goal orientation of Coaching Education departments students who were licensed in the team and individual sports. Relational scanning models were models aiming to measure the presence and degree of change between two or more variables (Creswell, 2012). In this study, the correlation between mental toughness and goal orientation were investigated in students who were in coaching education departments of universities, who create a team and individual sports as licensed.

The universe of the research was composed of students who were in coaching education departments of universities in the academic year of 2018-2019, and who created the team and individual sports as licensed. The research sample of the study was Coaching Education Department of the six state universities in Turkey composed of students who were licensed as team sports and individual sports. Participants consisted of 327 volunteer students selected by the easily available sampling method. If there was no confounding effect of other variables on the variable to be examined, and if it was related to basic human characteristics, the researcher can use this method if the range of the measured variable can be reflected in his sample (Erkus, 2011). Data belonging to these participants were excluded from the study, and a total of 312 data was reached. In addition, 43 participants were excluded by determining extreme values and the analysis continued with a total of 269 data.

Task and Ego Orientation Questionnaire in Sports: the questionnaire was developed by Duda \& Nicholss (1992). Task and ego orientation questionnaire in sports consist of 13 question items, seven of which are about ego orientation. In the original study on the questionnaire, the internal consistency of the questionnaire was determined as .79 for task orientation and .81 for ego orientation. In addition, the three-week test-retest reliability of the questionnaire was found as .68 for task orientation and .75 for ego orientation (Duda \& Nicholss, 1992). The questionnaire was adapted for Turkish Athletes by Toros (2001, 2004).In the adaptation study by Toros (2001), two factors, task and ego orientation, explained $58 \%$ of the overall variance, and the internal consistency values calculated by Cronbach and alpha were .87 for task orientation, .85 for ego orientation, and threeweek test-retest reliability .65 for task orientation and .72 for ego orientation.

Mental Toughness Questionnaire in Sports: the Sports Mental Toughness Questionnaire (SMTQ-14), developed by Sheard et al. (2009), which was used to determine the mental toughness levels of athletes, consists of 14 items. The inventory, which consists of three sub-dimensions (confidence, commitment and control) as well as general mental toughness, is of the four-point Likert type. Cronbach's alpha values for the sub-dimensions of the inventory were determined as .81 for the reliability subdimension, .74 for the commitment sub-dimension, .71 for the control sub-dimension, and .81 for the total internal consistency coefficient (Sheard et al., 2009). Mental Toughness Inventory in Sports, adaptation to Turkish was done by Altintas \& Koruç (2016). Cronbach's Alpha internal consistency reliability coefficient was found to be .70 in this sample of the Mental Toughness Inventory in Sports. Accordingly, the Mental Toughness e Inventory in Sports has a reliability coefficient that can be used in this sample. When evaluated in terms of subscales, the Cronbach Alpha internal consistency reliability coefficient of the confidence 
subscale, .66; Cronbach's Alpha internal consistency reliability coefficient of the commitment subscale was determined as .56 , and the Cronbach's alpha internal consistency reliability coefficient of the control subscale was determined as .6o.

The research data was collected from the Coaching Education Department of the six-state universities in Turkey. In this context, volunteer participants were informed about the questionnaires and it was stated that their answers would only be used for scientific research.

SPSS 25 statistical package program was used to evaluate the data obtained from the participants. The normality of the distribution of the data was tested with the Kolmogorov-Smirnov test and it was determined that the data showed a normal distribution. For the normally distributed data, the t-test was used for groups independent of parametric tests. Pearson's correlation coefficient was used to examine the correlation between the data. In this study, the error level was taken as .05.

\section{Result:}

Table-1: The correlation between task and ego orientation and mental toughness

\begin{tabular}{llllll}
\hline Variables & \multicolumn{1}{l}{ Confidence } & Commitment & Control & $x$ & $\mathrm{~S}$ \\
\hline Task & $.410^{* *}$ & $.310^{* *}$ & $-.208^{* *}$ & 3.55 & .772 \\
Ego & $.347^{* *}$ & -.107 & $-.269^{* *}$ & 3.29 & .847 \\
& & & $* *$ & Correlation is significant at the o.o1 level (2-tailed).
\end{tabular}

Table-1 indicated a positive medium level correlation between the task, ego and the confidence sub-dimension. There was a weak negative correlation between the task and ego and the control sub-dimension (Köklü et al., 2007).

Table-2: Independent group t test results according to the variable of sports

\begin{tabular}{|c|c|c|c|c|c|c|c|}
\hline Variables & Sports & $\mathrm{N}$ & Mean & SD & df & $\mathrm{t}$ & $\mathrm{p}$ \\
\hline \multirow[t]{2}{*}{ Task } & Individual & 126 & 3.48 & .786 & \multirow[t]{2}{*}{267} & \multirow[t]{2}{*}{-1.487} & \multirow[t]{2}{*}{.138} \\
\hline & Team & 143 & 3.62 & .756 & & & \\
\hline \multirow[t]{2}{*}{ Ego } & Individual & 126 & 3.19 & .785 & \multirow[t]{2}{*}{267} & \multirow[t]{2}{*}{-1.650} & \multirow[t]{2}{*}{.100} \\
\hline & Team & 143 & $3 \cdot 37$ & .893 & & & \\
\hline \multirow{2}{*}{$\begin{array}{l}\text { Confi- } \\
\text { dence }\end{array}$} & Individual & 126 & 3.09 & .679 & \multirow[t]{2}{*}{267} & \multirow[t]{2}{*}{-.522} & \multirow[t]{2}{*}{.602} \\
\hline & Team & 143 & 3.13 & .648 & & & \\
\hline \multirow{2}{*}{$\begin{array}{l}\text { Commit } \\
\text { ment }\end{array}$} & Individual & 126 & 3.66 & .378 & \multirow[t]{2}{*}{267} & \multirow[t]{2}{*}{1.144} & \multirow[t]{2}{*}{.254} \\
\hline & Team & 143 & 3.60 & .448 & & & \\
\hline \multirow[t]{2}{*}{ Control } & Individual & 126 & 3.71 & .387 & \multirow[t]{2}{*}{267} & \multirow[t]{2}{*}{3.064} & $.002^{*}$ \\
\hline & Team & 143 & 3.55 & .424 & & & $\mathrm{p}<.05^{*}$ \\
\hline
\end{tabular}

As per Table-2, the mean scores of the participants who participate in individual sports differed significantly in the "control" dimension compared to the participants who participated in team sports and were significantly differed from each other.

In Table-3, the mean scores of the participants aged 21 and under differed significantly in the "control" dimension compared to the participants over the age of 21.
Table-3: Independent group t test results according to age variable

\begin{tabular}{llllllll}
\hline Variables & Age group & \multicolumn{2}{c}{ Mean } & SD & df & \multicolumn{2}{c}{$\mathrm{p}$} \\
\hline Task & 21 yrs. \& under & 135 & 3.56 & .687 & 267 & .091 & .927 \\
& 21 yrs. \& older & 134 & 3.55 & .852 & & & \\
Ego & 21 yrs. \& under & 135 & 3.38 & .713 & 267 & 1.767 & .078 \\
& 21 yrs. \& older & 134 & 3.19 & .957 & & & \\
Confi- & 21 yrs. \& under & 135 & 3.07 & .697 & 267 & -1.055 & .293 \\
dence & 21 yrs. \& older & 134 & 3.16 & .624 & & & \\
Commit- & 21 yrs. \& under & 135 & 3.63 & .421 & 267 & -.020 & .984 \\
ment & 21 yrs. \& older & 134 & 3.63 & .414 & & & \\
Control & 21 yrs. \& under & 135 & 3.71 & .384 & 267 & 3.474 & $.001 *$ \\
& 21 yrs. \& older & 134 & 3.54 & .426 & & & $\mathrm{p}<.05$
\end{tabular}

\section{Discussion :}

In this study; according to the statistical analysis; between the "task" and "ego" sub-dimensions and the "confidence", there was a positive medium level, between the "task" and the "commitment" positively at a medium level, with the "ego" and the "commitment". There was a weak negative correlation between the "task" and "ego" sub-dimensions and the "control" sub-dimension. It was stated that a total of 156 male high schoolvolleyball players from the school team participated in a study in which the goal orientation of high school male volleyball players was examined, and that the mean task orientation was not related to ego orientation (Toros \& Koruç, 2005). In a study consisting of 143 amateur and 140 professional football players between the ages of 18 35, goal orientation was examined in amateur and professional football players. The results showed that amateur football players achieved significantly higher ego orientation and task orientation than professional football players. It was not observed that age and experience had an effect (Üngür, 2009).

The goal orientation of badminton players, a total of 56 athletes, 42 national athletes and 14 non-national athletes, took part where the badminton athletes had a higher ego orientation (Gencer, 2010). It was observed that elite and non-elite basketball players and those with high ego orientation get more pleasure (Toros, 2001). In our study, in order to reveal the differentiation of Task and Ego Orientation and Mental Toughness levels in sports according to the individual or team sports status of the participants, the mean scores of the participants who did individual sports were significantly different in the "control" dimension compared to the participants who did team sports. It was seen that the mean scores of the participants who did individual sports were significantly higher than the participants who didn't participate in team sports. A fundamental characteristic of athletes with high mental toughness was that these athletes claim to have the ability to cope with negative emotions such as competition anxiety. Mental toughness consists of strong personality, control, commitment and struggle structures. Clough et al. (2002) suggested that mental toughness consists of the 
concepts of control, commitment, struggle and confidence. While mental toughness is expressed as a person's good selfmanagement in the face of potentially stressful experiences, some studies emphasize that individuals can gain this feature through living over time. However, for mental toughness; It can be said that it is a structure that is understood when faced with negative events, experienced with what is experienced, and settled with gains in individuals over time (Fourie \& Potgieter, 2001). Today, it is an accepted fact that in addition to the physical competence of the athlete, psychological competence is also important to achieve high performance in the sports environment. The concept of mental toughness, which was accepted as a part of personality at first, has started to be considered as a psychological performance indicator for athletes. In a study in which Fox et al. (1994) examined the effect of task and ego orientation on motivation, they found that task-oriented children were more motivated than ego-oriented children. Similarly, Duda (1998) found significant differences between male and female students in goal orientation, according to his study on individual and team athletes in universities and high schools. Abele \& Alfermann (2001) found that task orientation was associated with intrinsic motivation, enjoyment of sports, determination against defeat, and medium difficulty goal selection. Gucciardi (2010) revealed that task-oriented athletes have high levels of intrinsic motivation, and also their mental toughness scores awere similarly high.

In our study, it was seen that the mean scores of the participants aged 21 and below in Sport Task and Ego Orientation and Mental Toughness levels differed significantly in the "control" dimension compared to the participants above the age of 21. It was seen that the mean scores of the participants aged 21 and under were significantly higher compared to those above the age of 21. It was estimated that mental toughness, which makes a significant contribution to athletes psychologically, is effective in achieving a successful performance. In the study conducted by Connaughton et al. (2008), it was concluded that age and mental toughness in sports were directly proportional, and accordingly, older athletes had higher mental toughness. Yildiz \& Yilmaz (2017) stated in their study on mental toughness and self-efficacy that mental toughness increases with increasing age. Yardimci et al. (2017), in their study with American football players, stated that the mental toughness levels of the 24-year-old and over group were higher than the younger ones. Unlike this study, Yildiz \& Yilmaz (2017) stated that as the age of sports increases, mental toughness increases. Mladenovic \& Truni (2019) investigated basketball players' goal orientation and mental toughness, and young basketball players showed an orientation towards the goal of reaching higher levels of their competence rather than status and normative achievement with others. According to the research results, the strongest component of mental toughness was the motivation and its weakest point was the ability to rebound. In contrast to our research findings, there were studies that detected a significant difference between mental toughness and age in sports (Cicioglu et al., 2019; Crust et al., 2014; Kurtay, 2018; Marchant et al., 2009; Nicholls et al., 2009; Yarayan et al., 2018) and did not report a significant difference (Crust, 2009).

In this study, the correlation between mental toughness and goal orientation was examined. Other statistical methods could be used to determine the difference between mental toughness and goal orientation of athletes. Examining the quantity and quality differences in this area would contribute to the field. It can be suggested that researchers' research on the same subjects should be handled in a more comprehensive and versatile way.

\section{References:}

Abele, A.E., Alfermann, D. (2001): Sport and exercise psychology: Overview (p. 14909-14913.). In N. J. Smelser \& P. B. Baltes (Ed.), International Encyclopedia of the Social \& Behavioral Sciences, Pub. by: Elsevier, Amsterdam.

Altintas, A., \& Koruç, B.K. (2016): Examining Psychometric Properties of The Sport Mental Toughness QuestionnaireSMTQ. Hacettepe J. Sport Sci., 27(4):162-171.

Bull, S.J., Shambrook, C.J., James, W. \& Brooks, J.E. (2005): Towards an understanding of mental toughness in elite English cricketers. J. Appl. Sport Psychol., 17(3):209-227.

Cicioglu, H.I., Demir, G. T., Bulgay, C., \&Çetin, E. (2019): Exercise Addiction Levels among Elite Level Athletes and Students of Sports Sciences Fac. J. Depend., 20(1):12-20.

Clough, P.J., Earle, K. \& Sewell, D. (2002): Mental toughness: the concept and its measurement (pp. 32-43). In I. Cockerill (Ed.), Solutions in Sport Psychology. Pub. by: Thomson Publishing, London.

Connaughton, D., Wadey, R., Hanton, S., \& Jones, G. (2008): The development and maintenance of mental toughness: Perceptions of elite performers. J. Sports Sci., 26(1):83-95.

Cox, R.H. (1998): Sport Psychology: Concepts and Applications. 4 Ed. The McGraw-Hill, p. 236-271.

Creswell, J.W. (2012): Educational research: planning, conducting, and evaluating quantitative and qualitative research. (4. Ed). Pub. by: Pearson Education Inc., USA

Crust, L. (2009): The relationship between mental toughness and affect intensity. Person. Indiv. Differ., 47(8):959-963.

Crust, L. (2007): Mental toughness in sport: A review. International J. Sport Exerc. Psycho., 5(3):270-29o.

Crust, L. (2008): A review and conceptual re-examination of mental toughness: Implications for future researchers. Person. Indiv. Differ., 45:576-583.

Crust, L., Earle, K., Perry, J., Earle, F., Clough, A., \& Clough, P.J. (2014): Mental toughness in higher education: Relationships with achievement and progression in first-year university sports students. Person. Indiv. Differ., 69:87-91.

Duda, J.L. (1998): Advances in Sport and Exercise Psychology Measurement: Sport Motivation and Perceived Competence. Pub. by: Fitness International Technology, 
TECHNOSCIENCE ARTICLE

Morgantown.

Duda, J.L. (1992): Motivation in sport setting: A goal perspecitive approach. In Roberts, G. C. (Ed.), Motivation in Sport and Exercise. Pub. by: Human Kinetics, Champaign, Illinois.

Duda, J.L., \& Nicholls, J.G. (1992): Dimensions of achievement motivation in schoolwork and sport.J. Edu. Psychol., 84(3):290.

Erkus, A. (2011): Scientific Research Process for Behavioral Sciences. Pub. by: Seçkin Publishing, Ankara, Turkey.

Fourie, S. \& Potgieter, J.R. (2001): The nature of mental toughness in sport. S. Af.J. Res. Sport, Phys. Edu. Recreat., 23:63-72.

Fox, K., Goudas, M., Biddle, S., Duda, J.L. \& Armstrong, N. (1994): Children's task and ego profiles in sport. Br. J. Edu. Psychol., 64:253-261.

Gencer, E. (2010): The relationship between locus of control, selfesteem and goal orientation, motivational climate in badminton players. Ovidius University Ann. Ser. Phys. Edu. Sport. Sci. Move. Health, 10(2):157.

Goldberg, A.S. (1992): Training the psychological dimension. Soccer I., 37(1):58-6o.

Gucciardi, D.F. (2010): Mental toughness profiles and their relations with achievement goals and sport motivation in adolescent Australian footballers. J. Sports Sci., 28(6):615625.

Jagacinski, C.M. \& Nicholls, J.G. (1984): Conceptions of ability and related affects in task involvement and ego involvement. $J$. Edu. Psychol., 5:909-919.

Jones, G., Hanton, S. \& Connaughton, D. (2007): A framework of mental toughness in the world's best performers. Sport Psychol., 21:243-264.

Jones, M.I. \& Parker, J.K. (2013): What is the size of the relationship between global mental toughness and youth experiences? Person. Indiv. Differ., 54:519-523.

Köklü, N., Büyüköztürk, S., \& Çokluk-Bökeoglu, Ö. (2007): Statistics for Social Sciences. Pub. by: Pegem Academic Publishing, Turkey.

Kurtay, M. (2018): Review the mental toughness levels of the football players in development leagues. Master of Science Thesis, Akdeniz University, Institute of Health Sciences, Department of Movement and Training Sciences, Antalya.

Luthans, F. (2002): Positive organizational behavior: Developing and managing psychological strengths. Acad. Manag. Exe., 16(1):57-72.

Marchant, D.C., Polman, R.C., Clough, P.J., Jackson, J.G., Levy, A.R., \& Nicholls, A.R. (2009): Mental toughness: Managerial and age differences. J. Manag. Psychol., 24(5):428-437.
Ambient Science, 2020: Vol. 07(Sp1); 380-384 DOI:10.21276/ambi.2020.07.sp1.ta17

Mladenovic, M. \& Trunic, N. (2019): Goal orientation and mental toughness of young Serbian basketball players. XXII Scientific Conference, FIS COMMUNICATIONS 2019" in physical education, sport and recreation. Book of proceedings. University of Nis, Serbia, Faculty of physical education and sport, Oct 17-19. Pp. 81-85.

Nicholls, J.G. (1984): Achievement motivation: Concepts of ability, subjective experience, task choice and performance. Psychol. Rev., 91:329-346.

Sheard, M., Golby, J., \& Wersch, A. V. (2009): Progress towards construct validation of the Sports Mental Toughness Questionnaire (SMTQ). Eur. J. Psychol. Assess., 25:186-193.

Stephens, D.E., \& Bredemeier, B.J.L. (1996): Moral atmosphere and judgments about aggression in girls' soccer: Relationships among moral and motivational variables. J. Sport Exerc. Psychol., 18(2):158-173.

Toros, T. (2001): The effect of goal orientation, motivational climate, and uniqueness and difficulty level of goals on life satisfaction in elite and non-elite male basketball players. Unpublished Master of Science Thesis, Institute of Health Sciences, Mersin University, Turkey.

Toros, T. (2004). Reliability and validity study of duty and ego orientation questionnaire for Turkish athletes. J. Sport Sci., 15(3):155-166.

Toros, T.\& Koruç, Z. (2005): The relationship between goal orientation and perceived motivational climate among high school volleyball players in Turkey. Hacettepe J. Sport Sci.,16:135-145.

Üngür, G., (2009): The relationship between goal orientation and perceived motivational climate in amateur and professional footballers.Master of Science Thesis, Institute of Health Sciences, Ege University, Izmir.

Walling, M.D., \& Duda, J.L. (1995): Goals and their associations with beliefs about success in and perceptions of the purposes of physical education.J. Teach. Phys. Edu., 14(2):140-156.

Yarayan, Y.E., Yildiz, A.B. \& Gülsen, D.B.A. (2018): Examination of mental toughness levels of individual and team sports players at elite level according to various variables. J. Int. Soc. Res., 11(57):992-999

Yardimci, A., Sadik, R., \& Kardas, N.T. (2017): The relationship between loneliness levels and sport mental resistance levels of American football players. J. Sport Sci. Res., 2(2):79-90.

Yildiz, A.B., \& Yilmaz, B. (2017): Investigation of the relationship between mental endurance and self-efficacy levels in athletes. 15th International Sport Sciences Congress 15-18 Nov, Antalya. 